\title{
Vibración del pasado perdido. Discursos aCERCA DE LA OTREDAD MAYA EN EL JAPÓN DE LA POSGUERRA
}

\section{Vibration from lost past. Discourses on the Maya OTHERNESS IN POST-WAR JAPAN}

\section{Fumiko Sukikara ${ }^{\star}$}

Resumen: En este trabajo presento algunas ideas producidas en Japón acerca de los mayas, específicamente después de la derrota en la Segunda Guerra Mundial. Fue justo en las primeras décadas de la posguerra cuando los japoneses se acercaron a la otredad maya y desarrollaron ideas e imágenes particulares. Mi interés se dirige hacia algunas voces que pretenden narrar el pasado maya buscando asociaciones con el de Japón. Señalaré principalmente dos grandes motivos presentes en los discursos: "las artes mayas" y "el misterio de la civilización desaparecida". Considero que estos dos han sido los motivos más difundidos y los que aparecen desplegados en varios tipos de exposiciones. Revisando trabajos realizados en esos años, este artículo muestra las condiciones históricas del momento y cómo influyen en la aparición de estos discursos, así como la discusión de estas ideas sobre los mayas en Japón.

Palabras clave: posguerra en Japón, nostalgia, otredad maya, antropología y arte, antropología y medios de comunicación

Abstract: I present in this work some ideas on the Maya produced in Japan

* Maestra en Diversidad Cultural y Espacios Sociales, Instituto de Estudios Indígenas, Universidad Autónoma de Chiapas. Actualmente es investigadora afiliada a dicho instituto $(06 / 2019$ - 05/2020). El proyecto actual es "Historia social de narrativas en el arte visual: el caso de arte japonés acerca de lo maya en la época de 1960". Líneas temáticas del interés: traducción e interpretación, oralidad y escritura. Correo electrónico: sukken17@googlemail. com.

Fecha de recepción: 14/08/2019, fecha de aceptación: 23/09/2019, fecha de publicación: 31/01/2020.

(cc) EY-NC-ND Páginas 210-240 
specifically after its defeat in the World War II. It is during the first decades of the post-war when the Japanese approached the other Maya and developed particular ideas and images about it. My interest is directed towards some voices that intend to associate Mayan past with Japan's own past. I am mainly pointing out to two motives in these discourses: "the Mayan arts" and "the mystery of the disappeared civilization." These two motives are, I consider, the most spread and transmitted out off various types of exhibits. By reviewing some works related to them, this article addresses the historical conditions in that time and how they influenced the rise and development of those discourses, as well as the discussion around the ideas of the Maya made in Japan.

Key words: post-war in Japan, nostalgia, the otherness Maya, anthropology and art, anthropology and media

\section{Introducción ${ }^{1}$}

Después de la derrota en la guerra, el pararme en Tokio reducido a ruinas, me hizo evocar sin querer la ciudad antigua de México, que fue destruida completamente por el español Cortés (Yoshino, 1963: 4)².

Al término de la Segunda Guerra Mundial la sociedad japonesa estaba buscando una recuperación a escala nacional, tanto en la economía como en la política. En Japón, toda la población había quedado agotada, en parte por la violencia de la guerra misma y de la legitimación interna, y en parte por la pérdida de todo, incluso de las creencias que se practicaban cotidianamente. "No vamos a querer nada, hasta que ganemos" fue lema de una propaganda estatal difundida entre el público durante la guerra. Tras la derrota, las Fuerzas Aliadas inmediatamente impusieron el control con la instalación del Cuartel General $(\mathrm{GHQ})^{3}$ en

\footnotetext{
${ }^{1}$ Este artículo surge de una investigación realizada para la elaboración de la tesis de maestría "Formación y transformación en la narrativa del Popol Vub: las publicaciones y las prácticas de traducción al japonés, 1928-1971” (Sukikara, 2019).

${ }^{2}$ En todo el texto, las traducciones del japonés al español son mías.

${ }^{3}$ El General Headquarters -cuartel general-. Después de la Segunda Guerra Mundial Japón fue ocupado por las Fuerzas Aliadas hasta la ratificación del Tratado de San Francisco del 1952. Como comandante supremo de las Potencias Aliadas, Douglas MacArthur supervisó la ocupación (Iwanami Shoten editores, 2013).
} 
Tokio, desde donde empezaron a operar la restauración del poder imperial y la instalación de un gobierno "democrático". El público japonés se encontró frente a un cambio radical, tanto político como social, que requería inevitablemente un esfuerzo para comenzar de cero.

Las experiencias de las acciones bélicas empezaron a ser expresadas ya a partir de los primeros tiempos de la posguerra por diversos artistas en literatura, cómics, películas y artes plásticas, entre otros medios. Un tema bien explorado, sobre todo, fue el del impacto de las bombas atómicas lanzadas en Hiroshima (6 de agosto de 1945) y en Nagasaki (9 de agosto de 1945), tratado como un golpe violentísimo e irreversible ${ }^{4}$. Un ejemplo significativo sería la imagen del hongo que se levantó en el cielo inmediatamente después del lanzamiento y que ha sido representada en varios medios literarios, así como visuales; incluso ha sido desplazada de su propio contexto y expuesta ya como un mero símbolo de la fuerza poderosa o del fin violento. Ha sido muy impactante la imagen de la destrucción ${ }^{5}$, al grado de dirigir la atención de los artistas hacia ella, provocando, cautivando y creando el deseo de expresar lo visto en su muy personal manera. Como testimonio de la destrucción, la figura de las ruinas, tanto de edificios monumentales como de campos abandonados, evoca el pasado violento y al mismo tiempo el esplendor del aquel tiempo. Así, guardando su característica bipolar, la destrucción se queda con la misma forma eternamente. A lo largo de la historia del arte, la admiración por las ruinas se ha convertido en tema en el clasicismo, en el romanticismo o en el fetichismo, provocando constantemente un sentimiento de nostalgia y melancolía.

Justamente en ese tiempo comenzaron a producirse y a consumirse ideas e imágenes acerca de los mayas en Japón. Lo interesante, que aquí se quiere destacar, es que en ese momento los intelectuales japoneses solían analizar los

\footnotetext{
${ }^{4}$ Por ejemplo, el personaje monstruoso Godzilla de una serie de películas (1954 a la fecha) fue originalmente descrito como una criatura producto de las pruebas nucleares. El origen del robot Atom, el personaje principal de manga de Osamu Tezuka (1951-1952), alude al carácter binario del poder nuclear, según su uso. Al final, la escena del manga Akira (1982-1990) escrito por Katsuhiro Otomo, es Neo Tokio en 2019, un mundo posterior a la Tercera Guerra Mundial; el relato comienza con una descripción de la nube en forma de hongo que surge encima de la llanura de Kanto, en las afueras de Tokio, como la señal del estallido de la guerra mundial.

${ }^{5}$ El tema de mi tesis de la licenciatura fue el estudio de estas imágenes representadas en la animación y los mangas japoneses escritos en el tiempo de la posguerra, y su asociación con las experiencias de sus autores durante la guerra. También se puede referir a una tesis destacada de Eriko Fujii, titulada "no-esteticismo de las ruinas", que me inspiró para este tema (2010).
} 
sitios arqueológicos en México, entre ellos los de los mayas, buscando un vínculo con el pasado japonés. Esas voces narran de modo nostálgico el pasado y lo identifican como algo compartido entre las dos historias, debido a su experiencia de destrucción, en unos casos a manos de otros.

Según su narrativa, el pasado pareciera no existir más, pues el de ambos se perdió. Un ejemplo destacable sería el de la frase citada para abrir el texto, aunque no se refiere a ciudades mayas sino a las ruinas de la ciudad de Tenochtitlán, en el centro de México. Esta frase se encuentra en la introducción del libro Mayas y Aztecas (1963) del ensayista Saburo Yoshino. El paisaje de Tokio le llevó a imaginar el destino de Moctezuma y, de manera amplia, el de los grupos étnicos de México (Yoshino, 1963: 4). Asimismo, Eiichiro Ishida, uno de los más conocidos entre los primeros antropólogos de la época de la posguerra, dice que quiso escribir sobre esta civilización antigua, los mayas, debido a que estaba fascinado por su misterio y su espléndido pasado desde que conoció las ruinas de sus ciudades antiguas (Ishida, 1971: 239-241) ${ }^{6}$.

Desde mi punto de vista, la narración nostálgica de lo pasado común se debe considerar como uno de los mayores motivos del primer acercamiento al sujeto maya, tan ajeno histórica y geográficamente para Japón. Las voces de artistas, escritores y antropólogos de la época hacen resonar como vibración estas ideas producidas entonces acerca de los mayas. Mediante la revisión de materiales publicados desde 1945 y hasta 1975, como libros, revistas y periódicos, es posible explorar aquí dos grandes motivos relacionados entre sí: "las artes mayas" y "el misterio de la civilización desaparecida". Esos temas, por ejemplo, aparecen notablemente repetidos en los títulos de libros publicados en ese tiempo (Tabla I). Considero que éstos son motivos destacados y significativos en el surgimiento del discurso acerca de los mayas en Japón, y que, de cierto modo siguen vigentes hasta el presente. Por otra parte, aunque a primera vista no se reconoce en ellos la contribución por parte del campo académico, los antropólogos han jugado un papel importante en la producción de estas narrativas. En aquel entonces eran pocos los antropólogos que podían dedicarse únicamente a su profesión, pues solían participar también en actividades tanto populares como artísticas. En los siguientes apartados trato de observar los dos discursos acerca de los mayas, las artes mayas y el misterio de la civilización desaparecida, tomando en consideración el papel de antropólogos en ellos.

\footnotetext{
${ }^{6}$ A Ishida le tocó viajar por el área maya desde México hasta Honduras, en 1953 y 1963 (Ishida, 1971).
} 


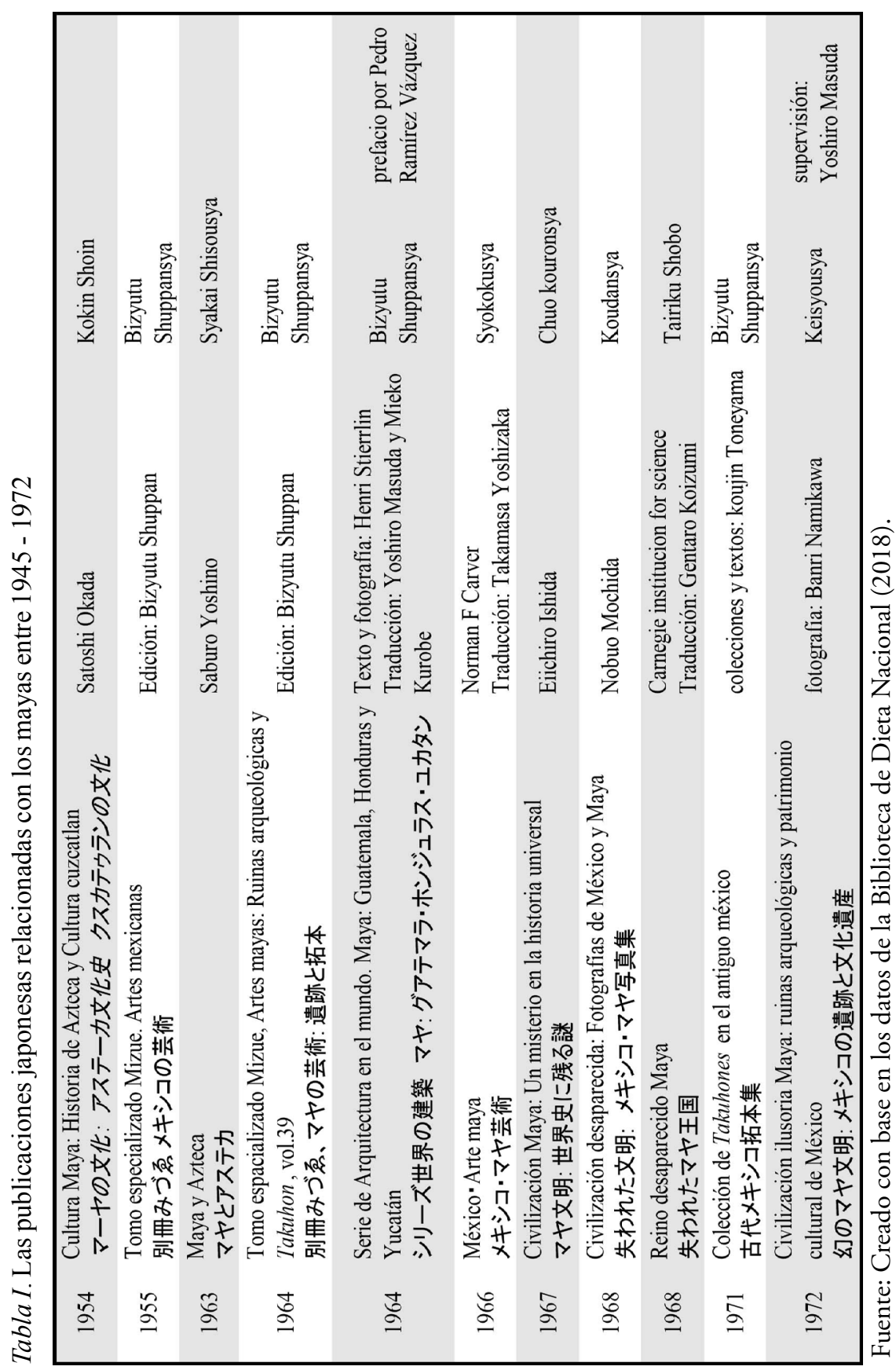




\section{Representaciones visuales y narrativas sobre los mayas en espacios artísticos \\ Crecimiento de los medios de comunicación y su presencia en actividades antropológicas}

Sin excepción, los antropólogos se enfrentaban a una honda ruptura por la derrota en la Guerra. Se encontraban en una condición muy difícil para producir trabajos de investigación profesionales por su propia cuenta debido a la falta de apoyos institucionales y de tiempos dedicados a la investigación. Es apenas en 1963 cuando procedió la formalización del apoyo institucional para la investigación en el extranjero, a cargo de la Secretaría de Educación, Ciencia y Cultura, y hasta un año después se autorizó el viaje al extranjero a todo el público (Iida, 2007: 263-269).

Algunos investigadores pudieron comenzar a realizar trabajo de campo en las zonas mayas antes de que las condiciones (de permiso y financiamiento) se hubieran dado, ya que fueron financiados por empresas privadas o instituciones extranjeras. Cabe señalar que es en aquel entonces cuando la antropología japonesa comenzó a aproximarse al sujeto maya y estudiarlo seriamente. La primera expedición destinada a la zona maya fue en 1953; Ishida hizo una visita a las ruinas mayas, y su viaje fue patrocinado por Wenner-Gren Foundation de Nueva York (Ishida, 1971: 7). Luego, en 1961, un grupo de la Universidad de Waseda realizó una expedición a la zona ${ }^{7}$. No obstante, parece que aún había dificultades para hacer investigación en el extranjero en la década de 1960. Una arqueóloga japonesa, Mieko Sakurai, quien estudiaba su licenciatura a mediados de la década de 1960, comenta que en aquel tiempo aún no estaban dispuestas las condiciones académicas bajo las cuales se pudiera realizar trabajo de campo en las ruinas mayas (Sakurai, 2004: 249). La economía japonesa no alcanzaba todavía una madurez que permitiera mandar a grupos de investigadores hasta las zonas arqueológicas de México y Centroamérica. Por ello la investigación dependía del apoyo que podía llegar desde las empresas privadas o desde otros países. El libro de Ishida, Civilización Maya: Un misterio en la historia universal,

\footnotetext{
${ }^{7}$ Una famosa expedición de antropólogos japoneses a la zona andina fue realizada en 1958 por un grupo de la Universidad de Tokio, dirigido principalmente por Seiichi Izumi. Hay otro grupo de la Universidad de Kobe que se dirigió a la Patagonia en 1957 (Iida, 2007: 245).
} 
publicado en 1967, es conocido como uno de los primeros textos sobre los mayas escritos por académicos japoneses (Ochiai, 2006: 9; Sakurai, 2004: 249) ${ }^{8}$.

Es decir, después de la derrota, antes de la recuperación de las funciones de instituciones tanto gubernamentales como académicas, los antropólogos estaban en la búsqueda de un espacio que les permitiera realizar su oficio. Esta situación ocasionó su acercamiento a los medios de comunicación. Ya a partir del principio de la década de 1950, los medios de comunicación comenzaron a operar como patrocinadores de las expediciones etnográficas. Además de ello, esta estrecha relación entre los dos agentes posibilitó de manera más provechosa la difusión de sus actividades al público, debido a que su financiamiento también cubría el proceso de exposición de los resultados, asimismo ofrecía la técnica de proyección. Las expediciones eran acompañadas de fotógrafos mandados por las compañías productoras de medios audiovisuales, que eran colaboradores de las editoriales de periódicos, y la grabación se transmitía en los cines pertenecientes a compañías productoras de películas (Iida, 2007: 241). Así, se produjeron varios documentales cinematográficos basados en expediciones académicas?.

En casos particulares relacionados con los mayas, dicha relación colaborativa se encuentra tanto en las exposiciones museográficas como en las expediciones ${ }^{10}$ (Tabla II). Los medios de comunicación ofrecieron recursos a las actividades antropológicas para proyectos y estrategias de difusión comercial, ya que también participaban en la organización de espacios para

${ }^{8}$ Cabe señalar aquí el interesante comentario que hace el antropólogo Tsubasa Okoshi, relacionado con la costumbre académica de los estudiosos japoneses, que presentaban al público la imagen de los mayas y de otros pueblos americanos. Ellos hacían sus estudios a través de la lectura de libros escritos en otros idiomas, principalmente en inglés, pero sin decir al público sobre sus fuentes, y los difundían como si fueran sus propios estudios. Esta costumbre continuaba hasta la década de 1980 (comunicación personal, 8 de febrero de 2019).

9 Esta colaboración tiene un inicio en 1953, cuando un grupo de investigadores de la Universidad de Kioto tomó la iniciativa de hacer investigación antropológica fuera de Japón. Ellos se fueron tres veces a la montaña Manaslu en el Himalaya, en su mayor parte gracias a la financiación por la casa editorial del periódico Mainichi. La segunda y tercera expediciones fueron documentadas por una compañía productora de películas asociada con dicha casa editorial y se proyectaron en cine en 1954 y 1956 (Iida, 2007: 235-240).

10 Según mi pequeña investigación sobre programas principales de televisión, la aparición de documentales temáticos de los mayas tuvo que esperar hasta 1974. Eso ocurrió en la transmisión de una serie producida por la productora nacional NHK titulado El legado hacia el futuro (Housou library [la biblioteca de emisión], 2018) 


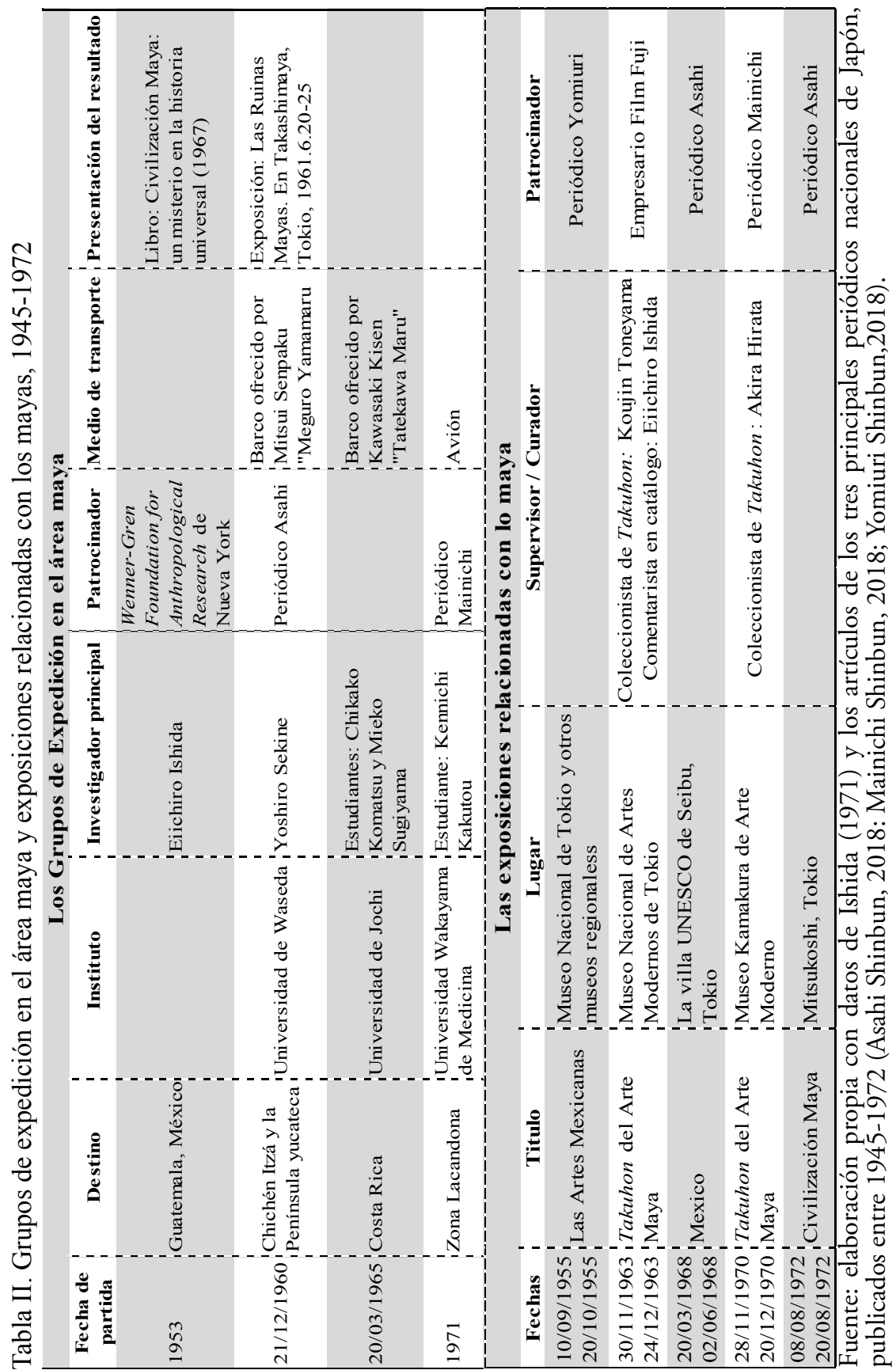


exposición. Así ellos colaboraban como patrocinadores de expediciones y de exposiciones, y por supuesto jugaban un papel fundamental en la difusión de esos proyectos entre el público.

Aquí quiero señalar dos puntos significativos para entender el papel de los antropólogos (principalmente) en los primeros tiempos de la posguerra en Japón. Primero, es notable un cambio radical en la estructura de la relación de poder en torno al campo de la antropología durante y después de la Segunda Guerra Mundial. La derrota significaba, particularmente, una doble pérdida para los antropólogos japoneses. Una fue la pérdida de espacios para su trabajo de campo, que hasta entonces habían sido las colonias y territorios asiáticos dominados por el Imperio Japonés. Al mismo tiempo perdieron patrocinadores de sus investigaciones, que hasta entonces habían sido las autoridades militares y el gobierno estatal ${ }^{11}$. Iida hizo un resumen puntual sobre este cambio sucedido alrededor del campo antropológico (Iida, 2007: 230): durante la guerra, las autoridades militares y burocráticas fueron las que cooperaban con los etnólogos dándoles el financiamiento y también "los objetos" de investigación. En el tiempo de la posguerra, en cambio, los que ocuparon el lugar del patrocinador fueron los medios de comunicación. Ellos tenían sin duda influencia decisiva sobre la dinámica del mercado de la información comercial.

El segundo punto es que mientras se encontraban en dificultades por las limitaciones políticas y financieras, algunos antropólogos interesados en el estudio de los mayas pretendían aplicar su profesión fuera del ámbito académico, especialmente en espacios artísticos. Ellos ocuparon un lugar como supervisores en publicaciones y exposiciones acerca del arte. Otros que lograron hacer expediciones en la zona maya presentaron los resultados de su trabajo en museos. Es decir, la exposición museográfica fue un espacio en el que los antropólogos empleaban su oficio de manera destacada en aquel entonces. Por ello, este tipo de espacio funcionó también como el formato más activo para visibilizar las ideas e imágenes sobre los mayas.

Lo importante aquí es preguntarse cómo se integró la parte científica en el espacio artístico en el que los objetos prehispánicos se exhibieron. A partir de ello, surgen cuestiones sobre la manera de disponer los objetos prehispánicos en las salas, así como sobre el mensaje de cada uno de los objetos, de las salas y ${ }^{11}$ Con respecto a esta cuestión, hay una discusión más amplia en el primer capítulo de Sukikara (2019). 
de la exposición en su conjunto. Estas cuestiones se discutirán en el siguiente apartado con el propósito de identificar ideas e imágenes de los mayas y cómo son reflejadas en el espacio artístico. Se inicia con "Las artes mexicanas", la primera exposición que expuso materiales prehispánicos de México en Japón.

\section{“Las Artes Mexicanas” en 1955: reflejo del pasado nacional de México}

En septiembre de 1955, en el Museo Nacional de Tokio, se inauguró la exposición "Las artes mexicanas", a través de un Convenio Cultural entre los Estados Unidos Mexicanos y el Japón firmado en 1954 (Hijikata, 25 de julio de 1955: 7). En ese momento se hablaba ya del éxito que había tenido el mismo proyecto en París en 1952 (Miyamoto, 11 de septiembre de 1955: 3). Se pueden conocer algunas impresiones que tanto el público como los artistas tuvieron de la exposición. El periódico Yomiuri, cuya casa editorial fue la misma patrocinadora del proyecto, dedicaba un amplio espacio a un artículo acerca de ella con los comentarios de los artistas (Hijikata, 1955; Miyamoto, 1955). Asimismo, en el otoño del mismo año, se publicaron un par de volúmenes de una revista especialmente dedicados a dicha exposición, en los cuales se

Figura I. Publicaciones especializadas sobre la exposición "las artes


Fuentes: Izq., (Yomiuri Shinbun Yomidasu, 2018); der., (Bizyutsu Syuppan, 1955) 
presentaron discusiones entre artistas y críticos de arte sobre la exposición y las artes mexicanas (Bizyutsu Syuppan, 1955) (Figura I, izquierda).

En el espacio del Museo Nacional de Tokio, frente a la escalera que lleva a la planta alta, estaba dispuesta la Cabeza de la Venta, la cual señalaba la entrada de la exposición (Miyamoto, 1955: 3). A partir de ella se encontraban once salas: de la primera a la tercera se presentaban artefactos prehispánicos, desde los olmecas hasta los teotihuacanos, zapotecos y palencanos, etc.; en la cuarta y quinta se exhibían obras coloniales y modernas; a partir de la sexta comenzaba la sección de las obras contemporáneas, incluyendo las pinturas de conocidos muralistas como Rivera, Siqueiros, Tamayo y Orozco (ibídem). En la exposición se presentaron en total mil piezas aproximadamente (Hijikata, 1955).

Lo notable es que el recorrido por las salas de "las artes mexicanas" fue organizado en orden secuencial de la historia mexicana. Es decir, aquí se puede identificar una doble forma de representar los artefactos prehispánicos: como una parte de la historia mexicana y, a su vez, dentro de la categoría del arte.

En primer lugar, se trata de un recorrido dispuesto en orden lineal, a lo largo de una narrativa de la historia mexicana. Esta manera de exhibir la historia como algo secuencial implica encuadrar en una totalidad de "lo mexicano" los objetos provenientes de diferentes lugares y de distintos tiempos, y se da una ilusión de la continuidad entre ellos. El crítico del arte Hijikata menciona en el periódico: "La tradición de la cultura antigua continuó y floreció en el arte moderno mexicano" (Hijikata, ídem). Las palabras del crítico de arte parecen mostrar claramente su aprehensión de la continuidad entre pasado y presente mexicano, por lo cual "la cultura antigua" se valora. Lo importante es que dicha alineación fue intencional, con el propósito de hacer la asociación entre lo prehispánico y el muralismo. Como sabemos, el muralismo mexicano surgido en los años de 1920 pretendía proyectar de manera artística "la historia mexicana”, incluyendo a la gente indígena, y crear la solidaridad a nivel nacional. Es decir, el recorrido de una sala a otra fue planteado para representar la trayectoria de la recuperación del "pasado" del arte mexicano.

En segundo lugar, es pertinente abordar el tema desde un punto fundamental: la categorización de los objetos prehispánicos como "arte". Este procedimiento se puede observar desde el principio del siglo pasado 
en Occidente; por ejemplo, Picasso y sus compañeros artistas reconocían que objetos "primitivos" de origen africano eran un "arte poderoso" y estos materiales se convirtieron en parte de sus colecciones, y a la vez en inspiración para sus obras (Clifford, 1995: 230). James Clifford señala que en los artefactos primitivos los artistas occidentales descubrieron capacidades humanas universales y ahistóricas, rescataron su alteridad y reorganizaron las artes no occidentales a su imagen (ibídem: 230-234). A partir de dicho redescubrimiento occidental los objetos primitivos han sido revalorados por la mirada moderna.

Parece que el impacto del arte del Otro, como fue percibido en el mundo artístico occidental, se compartió también en Japón durante el tiempo de la posguerra. Al inaugurarse la exposición "Las artes mexicanas", los artículos del periódico publicaron impresiones sobre "el arte mexicano", expresándolo con palabras como "desconocido"y "nuevo arte". Dicho discurso de lo "nuevo", presupone una comparación con el arte antiguo y clásico occidental. Los dos comentaristas encargados de escribir sus textos en el periódico Yomiuri mencionan la valoración realizada por Occidente sobre las artes mexicanas y pretenden comparar el arte occidental con el mexicano. Uno de estos comentaristas, el artista Miyamoto, comenta en su artículo titulado Nuevo mundo del arte: "Aquí vamos a percibir algo totalmente nuevo y a descubrir un nuevo arte y una nueva verdad" (Miyamoto, 1955). Sus narrativas dicen abiertamente en el periódico que se trata de un arte desconocido y presentan claramente la emoción ocasionada por el descubrimiento de la alteridad.

Además, después de la exposición de "Las artes mexicanas", la atención hacia estas, tanto contemporáneas como de la época prehispánica, creció a escala nacional. Según algunos artistas japoneses, esta exposición produjo un profundo impacto en los artistas jóvenes, quienes habían estado acostumbrados, quizás hasta el hartazgo, a las obras artísticas de estilo occidental y buscaban otras formas de expresión (Kato, 2008: 52). Entre ellos, Taro Okamoto y Koujin Toneyama se destacan por ser particularmente aficionados a los objetos prehispánicos. Okamoto conocía "las artes prehispánicas" de México a través de su compañero, el pintor francés Kurt Seligmann, quien le mostró fotos de las ruinas arqueológicas; estas imágenes y narrativas sobre la época prehispánica impresionaron a Okamoto (Nakano, 2004). Los dos artistas japoneses hicieron varias visitas a México en las décadas de 1950 y 
1960, y siguieron creando durante su madurez obras inspiradas en "las artes prehispánicas" (Kato, 2008: 53-51).

¿Qué es el espacio de las exposiciones de los objetos prehispánicos? Los objetos colocados en la exposición provenían de varios lugares: de museos, de galerías y de manos de coleccionistas. Antes de distribuirse en las salas, durante la clasificación, operan la exclusión, la inclusión y la selección prioritaria de objetos. Después de dicho proceso, finalmente cada uno de los artefactos se coloca en un espacio dispuesto para él. Aquí es inevitable considerar al papel del curador, quien practica la operación de la clasificación, fundamentándose en la valorización moderna de sus antecesores, así como en sus propias experiencias estéticas ${ }^{12}$.

Siguiendo a Walter Benjamin, en el proceso de clasificación se pueden observar dos prácticas discursivas. Por un lado, ocurre el desplazamiento del valor de cada objeto; se quita "su valor ritual" (o cualquiera otro que haya tenido) y a la par se aplica una revalorización por "su valor de exhibición" (Benjamin, 2003: 52). "Cuando el peso absoluto recae en su valor de exhibición, la obra de arte se ha convertido en una creación dotada de funciones completamente nuevas, entre las cuales destaca la que nos es conocida: la función artística” (ibídem: 54). Por otro lado, dicha práctica de revalorización resulta en la reconfiguración del sistema de conocimiento (Foucault, 1995; HooperGreenhill, 1992). Los artefactos "primitivos" así como "prehispánicos" se han proyectado a los ojos calificadores que tienen puestos los lentes de la modernidad, y se ordenan dependiendo de su nuevo valor artístico adherido por la mirada moderna. El acto de disponer los artefactos de cierta manera los ha constituido en el espacio de la exhibición como objetos de mundos auténticos y tradicionales, y otras veces como propios de mundos exóticos (Clifford, 1995: 236-240). El museo es susceptible de ser un lugar de preservación del pasado apropiado y ordenado, tanto de Nosotros como de Otros.

12 Aunque no se puede saber quiénes se dedicaron realmente a la curaduría, entre los mexicanos que tomaron parte en la organización de la exhibición se reconoce a los siguientes: el coleccionista de los pintores contemporáneos, Álvaro Carrillo Gil; el entonces representante del Museo Nacional de Artes Plásticas, Jesús M. Talavera; el entonces jefe del Departamento de Artes Plásticas de la Secretaría de Educación Pública y subdirector general, Víctor M. Reyes; entre otros (Instituto Nacional de Bellas Artes, et al., 1955). El entonces director general del Instituto Nacional de Bellas Artes, Miguel Álvarez Acosta, hizo comentarios en el catálogo de la exhibición. 


\section{Ejemplos de la reproducción de las imágenes del pasado por artistas japoneses}

Ahora, mediante la observación del ordenamiento en la exposición de "Las artes mexicanas", se pueden ver algunas influencias de las artes mexicanas en las japonesas ${ }^{13}$. Por un lado, después del encuentro con "el arte mexicano", algunos artistas jóvenes se inspiraron para repensar el pasado japonés e intentaron expresarlo en sus narrativas artísticas. Por ejemplo, Taro Okamoto, cuando fue encargado de la dirección de la exposición temática para la Expo’70 llevada a cabo en Osaka, creó la famosa escultura "la Torre del Sol". En su interior dispuso varios artefactos traídos desde África, Asia, Centroamérica y Sudamérica, y al mismo tiempo colocó sus propias piezas, como una titulada "el árbol de vida" y una figura inspirada por Coatlicue - una diosa azteca-. En aquel entonces Okamoto pretendía enunciar en voz alta la antítesis presente en la mirada normalizada en el campo artístico japonés, que le parecía una mera réplica de una categorización conformada en Europa ${ }^{14}$. Asimismo, en su libro Culturas tradicionales de Japón (Nihon no dentou) (1955) publicó una foto de Chac Mool de Chichén Itzá junto con trabajos clásicos japoneses, como una cerámica del período antiguo de Jomon y una pintura de Kourin Ogata, un pintor del período Edo (1658-1716) (Nakano, 2004)

Otra artista, Saori Akutagawa, hizo un par de murales en 1957 que trataron de Kojiki, un relato considerado como parte principal de la mitología japonesa. Sus piezas fueron inspiradas por los murales mexicanos, sobre todo de Rufino Tamayo (Hozaki, 2018: 1). Ella misma hacía comentarios sobre las artes mexicanas contemporáneas, diciendo que son narrativas con el potencial de relatar la pasión y el poder intenso que coexisten tanto en las figuras de los artefactos de hace miles de años, como en las artesanías (ibídem). No obstante, sus piezas de los murales de Desde Kojiki no fueron simple imitación de los murales mexicanos; Akutagawa consideró dar a sus obras ${ }^{13}$ No se puede elaborar una conclusión resumida con datos suficientes, por la falta de los materiales empíricos necesarios y por las limitaciones del tiempo. Sin embargo, considero que este tema sugiere un aspecto significativo para investigaciones futuras.

${ }^{14}$ Okamoto comenta claramente que su interés en "las artes antiguas" proviene del rechazo de la belleza moldeada al modo occidental como única forma; es decir, es el rechazo de "El Arte" particularmente nacido, desarrollado y aprobado en Occidente. "Cuando hablo de las artes de Centroamérica y Sudamérica, a mí me recuerdan no sólo de las mayas, aztecas e incas, sino también de las jomones, escitas, y celtas." (Okamoto, 1975: 99). 
una forma artística más pertinente para la mitología japonesa, lo que expresó en una forma "tradicional" llamada Emakimono, que relata la historia con ilustraciones secuenciales en un rollo horizontal (ibídem; Figura II). Se debe considerar que, como tendencia general del arte japonés en aquel tiempo, la tradición japonesa estaba siendo reconocida entre los artistas de vanguardia, y Okamoto fue uno de ellos. En dicho contexto, la forma del arte mexicano contemporáneo, que pretendía retomar lo prehispánico en sus expresiones, motivó a los artistas japoneses a recuperar su propia tradición.

Figura II. Una pieza de la Serie de Desde Kojiki (1957), Saori Akutagawa.

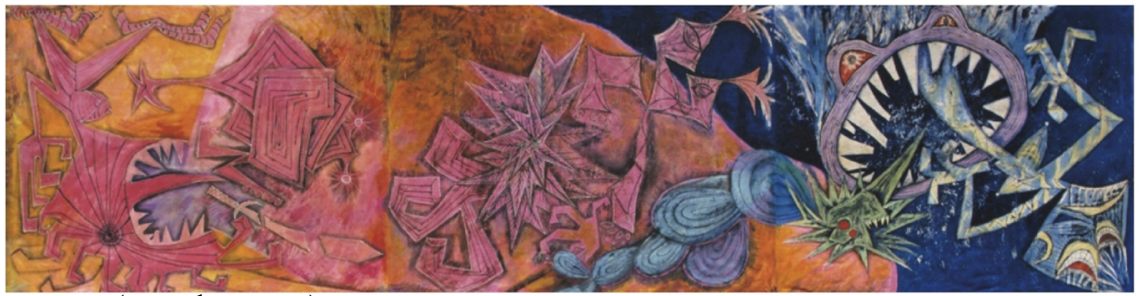

Fuente: (Hozaki; 2018)

Existe también otra imagen visual indicativa de la mirada japonesa dirigida a la otredad maya. En julio de 1955 el dibujante de manga conocido como precursor de este formato, Osamu Tezuka, publicó el capítulo titulado "Hombre congelado" de la serie de Tetsuwan Atom. En él dibujó una imagen de pirámide con la referencia a la civilización maya (Tezuka, 1999: 45-74). Aquí se nota la confusión del autor entre las civilizaciones antiguas maya y egipcia, debido a que aparece la esfinge junto con la pirámide (Figura III). Seguramente el dibujante Tezuka tuvo una fuente distinta a la exposición de 1955, ya que su manga fue publicado dos meses antes de la inauguración.

Lo interesante es que la asociación entre la civilización maya y la egipcia no es una invención personal de Tezuka, sino de aventureros occidentales de un siglo anterior. Ellos relataron la historia del origen y del fin de la civilización maya, creando historias a su propia imagen, a su vez reflejadas en la mirada occidental de la otredad maya. La asociación de la civilización antigua y el mundo imaginario dio ideas fantásticas al dibujante Tezuka y a sus seguidores, quienes crearon en sus obras relatos inspirados en dicha forma narrativa. Por ejemplo, Tezuka publicó la serie Mitsume ga toru-Hombre de tres ojos- en la década de 1970, que trata de un joven descendiente de la civilización Moó. En 
su manga, Moó está figurada como una civilización más avanzada que nuestra sociedad. Como veremos más adelante, la civilización Moó es una creación de un antropólogo amateur Le Plongeon, que asoció las ruinas mayas con una civilización imaginaria a la que llamó Moó. Alrededor de 1970 comienza a circular en Japón este tipo de narrativa cuyos motivos están situados en el lindero entre el pasado y el mundo ficticio. El público japonés la consumía como entretenimiento. Examinaré en el siguiente apartado la invención occidental de la civilización maya y la reproducción de ella en las décadas de 1960 y 1970 en Japón.

Figura III. Las representaciones de la civilización maya en el manga Tetsuwan Atom.


Fuente: (Tezuka, 1999)

\section{Mayas entre el pasado y el mundo imaginado}

La pasión del estudio de lo maya, que habia comenzado a ser exaltada por Stephens [John Lloyd Stephens] se calmó con el tiempo. Sin embargo, eso no significa su desaparición completa. Un puñado de aficionados tanto como de especialistas pretendia seguir sin cesar dando sus esfuerzos, con firme voluntad de abrir la puerta oculta.

Ya comenzó la primera página de la historia. Va vislumbrándose la figura de la única civilización antigua que habia quedado cubierta por el velo del misterio (Koizumi, 1976 [1968]: 22, anotación entre corchetes de la autora). 
Este fragmento fue tomado de una publicación japonesa titulada Reino desaparecido Maya -la misteriosa etnia desaparecida en la peninsula de Yucatán (Ushinawareta Maya oukoku -yukatan hantou ni kieta maboroshi no minzoku), "traducida” por Gentaro Koizumi (1976 [1968]). A pesar de que Koizumi se presenta como traductor, puse entre comillas "traducido" puesto que lo que hizo Koizumi no fue una traducción textual, sino que interpretó de manera propia las fuentes. Estas fueron mencionadas en el epílogo: la investigación realizada por Sylvanus Morley y los documentos archivados en varios institutos académicos estadounidenses, principalmente el Instituto Carnegie y el Smithsoniano (ibídem: 293).

La lectura del título, el índice y los contenidos de dicha publicación japonesa nos harían dudar que el libro estuviera basado en un texto escrito por autoridades científicas de un instituto académico. Los capítulos se titulan "la gente antigua y los alienígenas", "el grupo negroide étnico misterioso", y "Atlantis y los mayas", etc. Efectivamente, la lectura de sus contenidos me ha llevado a un mundo fantástico inventado. El "autor" Koizumi acentúa en su texto los aspectos ocultos de la civilización maya desaparecida-véase el fragmento citado arriba-, asociándolos a las narrativas de ese tiempo acerca de cuestiones consideradas misteriosas, irreales y de fantasía, por ejemplo, con el relato del continente perdido de la Atlántida.

Por un lado, hay que tomar en cuenta que el libro de Koizumi no es el único en el que se adjetiva a la maya como "civilización desparecida" o "misteriosa", entre las publicaciones japonesas relacionadas con ellos entre 1945-1972 (véase Tabla I). A partir del final de la década de 1960 en Japón, comenzaron a publicarse diversas series nombradas "sitios ocultos" o "civilizaciones desaparecidas". En ellas se abordaron historias ocultas de lugares desconocidos tanto nacionales como extranjeros, y se introdujeron sus historias en un lindero entre el pasado imaginado y la ficción. Efectivamente, este tipo de series se puso de moda en esa época y fueron consideradas precursoras de un tipo de ocultismo en Japón ${ }^{15}$ (Iikura, 2009).

${ }^{15}$ En el diccionario del japonés Kojien, el ocultismo se define como "la creencia y el estudio del 'poder oculto' que no ha sido probado en el ámbito científico y empírico" (Iwanami shoten editores, 2013). Según el Diccionario del español de México, el ocultismo es definido como: 1. "creencia en las realidades ultra-sensoriales (no empíricas), inaccesibles al uso exclusivo de la razón, y que desafían las leyes de la naturaleza”. 2. "conjunto de ciencias ocultas o conocimientos 
Por el otro, adjetivar la civilización maya como "desaparecida" y "misteriosa" conduce igualmente a una narrativa que ya se había inventado y condensado a lo largo del tiempo, a partir del período del "descubrimiento" de los sitios arqueológicos por los viajeros occidentales. Supuestamente, en el campo autorizado actualmente por la Ciencia no se podría asociar a los mayas con la Atlántida u otros lugares imaginarios. Sin embargo, dicha asociación entre el espacio antiguo y el imaginario fue inventada por los intelectuales, artistas y académicos occidentales, quienes hicieron viajes en el siglo XIX con el propósito de "descubrir" las ruinas de sitios ubicados en el área de Centroamérica. En aquel entonces, los viajeros aficionados a la arqueología y los mismos arqueólogos y antropólogos fueron los actores históricos que romantizaron y crearon una retórica específica sobre los mayas, como una civilización antigua y misteriosa que ya había desaparecido. Vale la pena seguir brevemente el proceso de la romantización de la civilización maya por Occidente en el tiempo de los viajeros aficionados a la arqueología.

\section{Invención occidental: surgimiento del discurso del "misterio de la civilización maya desaparecida"}

La apertura del segundo "descubrimiento" de América fue ocasionada por la expedición del escritor estadounidense John Lloyd Stephens y su colaborador el artista británico Frederick Catherwood (Evans, 2004: 44-87; Escalona, 2017). Los relatos de sus viajes, publicados en los libros titulados Incidents of Travel in Central America, Chiapas and Yucatan (1841), e Incidents of Travel in Yucatan (1843), fueron escritos en un tono familiar con imágenes asombrosamente detalladas (Evans, 2004: 45). Se volvieron muy populares entre la gente de clases altas y medias, debido a su precio accesible. Posteriormente, los aventureros aficionados a la arqueología organizaron sus propios proyectos dirigidos a la exploración de las ruinas prehispánicas.

El período del final del siglo XIX y hasta el principio del XX es considerado como la última etapa en que los amateurs habían podido colocarse en el campo del estudio arqueológico (Evans, ídem: 1-9). Efectivamente, en esta reunidos a este respecto, y las técnicas destinadas a percibir y captar el poder de estas realidades. Su práctica se remonta a la más alta antigüedad y se basa siempre en la magia que trata de evocar los poderes ocultos por medio de rituales, para cambiar el orden de la naturaleza, como llamar a los muertos para conocer el futuro; utiliza fetiches para conseguir la muerte o la resurrección de personas, etc. Entre las principales ciencias ocultas están: la alquimia, la necromancia, la astrología y la cábala." (Lara, 2011: 1188). 
época fueron notables los avances de la tecnología arqueológica, sobre todo en torno a la fotografía y al molde de yeso para hacer réplicas. Mientras tanto, el incremento de los conocimientos acerca de los orígenes de los grupos étnicos en el área actualmente llamada Mesoamérica, así como acerca del sistema de escritura y de calendarización, aún no correspondía a dichos avances tecnológicos (ibídem: 127). Alrededor de 1915, cuando comenzó a haber resultados "científicos" de investigación - por ejemplo, los datos arqueológicos y el desciframiento de glifos mayas-, las figuras de los amateurs fueron reemplazados por especialistas arqueólogos, quienes fueron patrocinados por institutos académicos como el Instituto Smithsoniano (ibídem: 8-9).

Fue en la etapa previa al reemplazo de amateurs por académicos autorizados cuando comenzaron a divulgarse las narrativas imaginarias acerca de "las civilizaciones desaparecidas". Se consideran dos condiciones contextuales. Por una parte, en aquel entonces México como unidad nacional se encontraba en una situación difícil. En una época muy próxima al estallido revolucionario, el país revelaba una profunda inestabilidad política y una dificultad para construir una totalidad sociocultural (ibídem: 5). En cambio, en el momento posterior a su guerra civil, Estados Unidos se situaba en una condición económica e industrial bastante sólida, lo que de algún modo permitió desarrollar exploraciones en casi toda Latinoamérica, con el interés de establecer su influencia territorial y política en la región (ibídem: 9).

Por otra parte, bajo una situación de escasez de información fidedigna, los viajeros occidentales aficionados a la arqueología promovían la publicación de textos sobre sus propias experiencias e ideas, algunos de los cuales estaban basados en su visión inventiva. Esto los llevó a mitologizar el pasado de México y Centroamérica (ibídem: 2). Por ejemplo, al hacer el descubrimiento históricamente importante del manuscrito colonial del fraile Diego de Landa, el abad francés Charles-Étienne Brasseur de Bourbourg ${ }^{16}$ asoció una parte de ese manuscrito con el relato de Atlántida, (ibídem: 113-114). Asimismo, el "arqueólogo" británico Augustus Le Plongeon descubrió una famosa estatua en Chichén Itzá en la década de 1880 y le dio nombre como Chac Mool. En aquel entonces el arqueólogo creó una historia trágica que habla de un vínculo de esta estatua con la Esfinge egipcia (ibídem: 126-152).

${ }^{16}$ Él es quien tradujo y publicó en 1861 el manuscrito del fraile Francisco Ximénez, y lo llamó primeramente Popol Vuh. El título completo de su versión francesa es Popol Vuh, le Livre sacré des Quichés. 
Estos discursos de Le Plongeon y Brasseur de Bourbourg no fueron los únicos que se mencionaban entre las voces de intelectuales occidentales. Antes y después de ellos aparecían diversas disputas infundadas acerca del origen y la desaparición de la civilización maya. Sin excepción, estas disputas se habían fundado en visiones personales, y a la vez en una perspectiva etnocentrista occidental (para más ejemplos, véase Evans, 2004). Esas disputas nos permiten reconocer el origen y el desarrollo del discurso del "misterio de la civilización maya desaparecida" en el mundo occidental. Al entrar al siglo XX los arqueólogos amateurs perdieron su lugar por el crecimiento del espacio autorizado por "la ciencia" -por ejemplo, las excavaciones y el desciframiento de los glifos a cargo de "los mayistas", como Morley y posteriormente Thompson; ambos pertenecientes al Instituto Carnegie-. A pesar de la desaparición de los amateurs, hasta nuestro tiempo "el misterio" ha estado presente como algo que deben confrontar los especialistas de los "estudios de los mayas". De igual manera, en el mundo de la ficción -en la literatura, el cine y la animación, etc.- la civilización maya desaparecida ha circulado como elemento del discurso del misterio ${ }^{17}$.

¿Cuáles son las implicaciones del discurso del "misterio de la civilización desaparecida"? Castañeda (1996) cuestiona la forma de tratar estas dos ideas, "misterio" y "desaparecido", como si fueran sucesivas y tuvieran continuidad. Este pensamiento fue provocado por el deseo de mostrar un progreso científico y arqueológico entre el siglo XIX y el XX (ibídem: 134). El mismo conjunto definido como "la civilización" ha sido incorporado al misterio, debido a que se consideraba que esto era el rasgo y la esencia de la gente que producía esta totalidad. El discurso construido con dicha asociación lleva al impulso por recuperar permanentemente su origen, a descubrir su nacimiento.

En cambio, en lugar de hacer la incorporación, Castańeda invita a considerar el "misterio" y el "desaparecido" como dos distintas metáforas políticas de dos discursos occidentales acerca de la otredad maya. Por un lado, es el discurso de la otredad situada dentro del espacio de "lo mismo", y por la otra, es el discurso de la otredad situada fuera de ello: en "algún espacio" (ibídem). La primera es una figura que ha provenido de las fábulas de la ciudad dorada, incluyendo la de Atlántida del Mediterráneo. La otra plantea,

${ }^{17}$ Recuerden la película monumental en este sentido, Indiana Jones y el reino de la calavera de cristal (2008), y el libro de Erich von Däniken, Chariots of the Gods?, que indican que Palenque, la ciudad maya antigua, había sido fundada por los alienígenas (Evans, 2004: 163n. 3). 
en cambio, una alteridad exógena que tendría un origen común del que surgió la perspectiva del canibalismo y salvajismo, así como del orientalismo (ibídem $)^{18}$. Estos dos discursos están fusionados en la metáfora de "el misterio de la civilización desaparecida". En resumen, esta forma discursiva se configura en un conjunto de ideas (tanto científicas como populares) que conciben a los mayas simultáneamente como un reflejo-otredad de la civilización occidental. La narrativa de "lo desaparecido", y por tanto la discusión sobre el origen de los mayas, ha permanecido dentro del discurso del misterio romantizado, como un debate irresoluble, que además reafirma la posición ambigua de la civilización maya.

\section{Escena del "misterio" desde la visión japonesa}

Ahora bien, la discusión se enfoca en la mirada japonesa hacia los mayas en el contexto socio-histórico del final de los años sesenta. Se examinan los factores particulares que generaron el discurso del "misterio de la civilización maya desaparecida”. En aquel entonces en Japón se daba una popularización de las narrativas sobre los lugares desconocidos y desaparecidos, tanto locales como extranjeros. Estas han sido llamadas Hikyo en japonés y los mayas han sido narrados dentro de esa categoría. Por ejemplo, el libro El Reino maya desaparecido de Koizumi (1976) formaba parte de la serie editorial de "las civilizaciones desaparecidas". Koizumi es el "traductor" de varios libros de la misma serie ${ }^{19}$, y Tairiku Shobou, la editorial de estos libros fundada en 1967, dice estar especializada en historias "no ficticias", sobre todo en la serie de Hikyo (Iikura, 2009: 26).

Las series de Hikyo publicadas en estos tiempos, incluyendo la de Tairiku Shobou, se caracterizaban por una forma de la narración "no ficticia"; las narrativas mismas se construían como si fuera experiencias reales de los autores. El autor o "el traductor" cuenta el relato en detalle, con información geográfica e histórica, asimismo con el lenguaje que pretendía hacer percibir a los lectores

\footnotetext{
${ }^{18}$ Para la discusión sobre la otredad, en general hay otros autores que mencionar. Por ejemplo, Said (1997) sería uno de los fundamentales. Sin embargo, para el caso particular de la otredad Maya resulta más adecuado Castañeda por la perspectiva de la ambigüedad que señalo aquí.

${ }^{19}$ Por ejemplo, El continente desaparecido Mú (1968), los descendientes de Mú (1970), y el reino misterioso Azteca (1968) son firmados por Koizumi (Koizumi, 1976: 295). Según la referencia editorial, los autores de sus fuentes son James Charchwood de los primeros dos libros y el Instituto Carnegie del último.
} 
la continuidad temporal y espacial con la escena de la narración. Todo eso era parte de las técnicas para generar sentido de "realidad" en el producto. Por esa misma razón se ponía como autor el nombre de los investigadores y de los institutos académicos occidentales, dejando al "traductor" en un lugar secundario, atrás de ellos.

El libro El reino desaparecido maya, de Koizumi, comienza con las dos historias del descubrimiento occidental: una historia del viaje de John Lloyd Stephens por Copán con el acompañamiento de Frederick Catherwood, y otra de la trayectoria del fraile Francisco Ximénez, quien encontró "un libro de la comunidad" identificado como Popol Vuh. Las dos historias contienen la vida personal de estos personajes históricos y la motivación que los llevó a hacer el "descubrimiento". Además, la narración tiene una característica palpitante, sobre todo al momento de hablar sobre la escena del viaje. El libro inicia con las siguientes palabras:

Hasta el fondo de la selva, del mar de árboles, no llegan los rayos del sol. Cuando los indios cortan las ramas y las plantas con la sierra, sale débilmente una claridad.

Mana el agua al pisar en el suelo lleno de las hojas caídas, y suena el zumbido de los insectos venenosos. Stephens y Catherwood sangran de los pies y manos, que se pinchaban con las espinas de los arbustos, sus ojos están congestionados por la inflamación, y sus párpados siguen hinchados y enrojecidos (Koizumi, 1976: 9).

Aparte del manejo del lenguaje dramatizado, el texto se caracteriza también por incluir los datos reales para localizar los viajes en un espacio existente. Por ejemplo, al relatar la expedición hacia las ruinas de Piedras Negras, dirigida por John Alden Mason, entonces profesor de la Universidad Península, primero nos hace saber las características geográficas de la localidad y una breve historia de la península Yucatán y del Río Usumacinta. Según el autor, dicho río está localizado en el centro del triángulo de la zona de la civilización maya, entre Copan, Uaxactún y Palenque; por eso fue llamado "el río madre de la cultura maya" (ibídem: 28). También presenta algunos personajes locales, por ejemplo, "los chicleros", quienes buscan el árbol del chicozapote caminando en las selvas. El autor comenta que estos encontraron las ruinas, 
pues el chicle y la arqueología tienen una conexión inseparable (ibídem: 35). De igual manera, los mapas y las fotografías jugaron el papel de visibilizar la situación de la excavación en las ruinas.

Así, en el texto de Koizumi se encuentran varias técnicas narrativas interesantes: el relato de los personajes históricos; la mención de datos geográficos, biográficos e históricos; la transmisión vívida del camino de la expedición con un tono creíble y a la vez dramático. Estas técnicas se entrelazan en el texto y provocan el efecto narrativo de las experiencias de los personajes históricos del "descubrimiento", como si se compartiera el tiempo y el espacio con los lectores. La narrativa entretejida con estas técnicas construye un espacio imaginario como si fuera existente.

Aún más, estas experiencias de búsqueda de los objetos llegan al final a lo oculto de "la desaparición", sin que llegue realmente a saberse el origen o el final de la civilización maya. Es decir, el relato se cierra con "el misterio". Koizumi concluye el texto con las siguientes palabras:

Por supuesto, hay un acontecimiento destructivo llamado la Conquista espańola. A pesar de ello, ¿en dónde los mayas dejaron caer su propia historia? En el presente los millones de indios mayas siguen en la vida tradicional.

La gente del reino antiguo maya, en su vida y cosmología, se fundamentaba en la teoría de la circulación y de la regeneración, las cuales han permanecido en la profundidad del corazón de los indios mayas; con el tiempo extensivamente largo, ¿se espera un día que la civilización caída vuelva a despertar con un nuevo suspiro? (ibídem: 291).

En resumen, en el texto de Koizumi, que forma parte de la serie japonesa de Hikyo, se encuentra el discurso del "misterio de la desaparición", igual que en las publicaciones de los viajeros occidentales de los dos siglos pasados. Sin embargo, lo importante es que el constructo en las series japonesas se debe diferenciar del discurso occidental, por lo menos en dos cuestiones: el tiempo histórico distinto y la perspectiva de la narración, dirigida hacia la escena del misterio.

Las publicaciones japonesas de ese momento son productos muy posteriores al surgimiento del discurso sobre los mayas en Occidente. Además, los autores japoneses no son los mismos viajeros que visitaron las ruinas. 
En la situación política de aquel entonces, salir del país era difícil para la mayoría de los japoneses y estaba limitado a pocos políticos y especialistas. En dicho contexto, las experiencias de la expedición y el "descubrimiento" del objeto misterioso son prestadas, citadas y "traducidas" de los productos occidentales. Es decir, las narrativas japonesas tenían una mirada desde un ángulo particular: eran un reflejo del discurso occidental. En este sentido, es un factor muy efectivo incluir en la narración las experiencias de los mismos viajeros occidentales. Así como el reflejo de las miradas hacia la otredad maya, los viajes de los personajes históricos occidentales formaron parte del juego de la reproducción de la narración. Efectivamente, el lenguaje de los textos japoneses se puede considerar como el de un reportero que no se sitúa en la misma escena histórica, pero transmite la situación con voz vívida, como si estuviera allí.

Tomando en cuenta lo anterior, se puede decir que la perspectiva hacia la otredad maya desde Japón se comparte con Occidente, pero al mismo tiempo no es igual. El propósito editorial de las series de Hikyo de los años sesenta en Japón no se dirigía al dominio de los conocimientos sobre la otredad Maya, ni a la comprobación de la historia, sino a la diversión de los lectores o a su curiosidad por conocer objetos extraños. En este contexto, los sitios mayas y otros lugares ocultos de Hikyo se convierten en objeto del consumo para satisfacer el deseo de conocer los lugares desconocidos y ajenos a la vida cotidiana. "El misterio" es una reproducción de un discurso que ya se había construido en Occidente desde hacía un siglo y que, a su vez, se había transformado en el producto de la industria cultural de Japón.

\section{Frutos técnicos de la colaboración entre antropólogos y medios de comunicación}

Hay otros aspectos en la construcción de la versión japonesa del "misterio de la civilización desaparecida” que tienen que ver con la dinámica antropológica en el contexto muy particular de la posguerra. En virtud de la liga con los medios de comunicación (conveniente para ambas partes), la antropología pudo sobrevivir en una condición complicada durante el tiempo inmediatamente después a la derrota en la Guerra. Al pasar el tiempo, a mediados de la década de 1960, comenzó a disolverse el pacto entre estas partes por varios factores 
sociales $^{20}$. Fue entonces cuando comenzaron a aumentar las publicaciones temáticas de Hikyo (Iikura, 2009: 33-36, Kaneko, 2009: 56-59). Por un lado, la temática del lugar misterioso comenzó a consumirse de manera amplia mediante publicaciones y transmisiones de televisión, justamente al liberarse de la relación colaborativa con la antropología (Kaneko, 2009: 59). Entonces los medios de comunicación ya no necesitaban manejar los lenguajes complejos ni los contenidos teóricos implicados en la participación académica. La editorial de Hikyo compuso textos con expresión e imaginación abiertas, sin aquellas limitaciones.

Por el otro lado, se ganó un fruto técnico gracias a una incorporación previa: la técnica narrativa de aromatizar el texto con el incienso de "la verificación científica”. Cuando los medios de comunicación tenían un pacto con la antropología, los resultados de la expedición se editaron y expusieron frente al público en exhibiciones, publicaciones y documentales. Durante esta colaboración, los productores de los medios aprendieron cómo construir la narración sobre las experiencias de los antropólogos, usándolos para dar una sensación de "veracidad" al producto (Iikura, 2009). Los dispositivos que producían dicho efecto consistían en mostrar las informaciones "científicas" de la geografía y la historia, basadas en investigación realizada por antropólogos (ibídem: 20). Posteriormente estos datos "antropológicos" se hicieron uno de los fundamentos de productos de editoriales como las series de Hikyo. En resumen, la narrativa en el texto de Hikyo ha sido constituida por una combinación entre la liberación del pacto con la academia -el lenguaje creativo con el tono dramático-, y el fruto del mismo pacto -el aroma de "veracidad"-.

Lo interesante es que la serie de Civilización desaparecida de la editorial Tairiku Shobou se enfoca más en el continente americano que en Asia o en otras regiones del mundo ${ }^{21}$. Antes y después de la Segunda Guerra Mundial, la otredad para el Imperio Japonés estaba ubicada principalmente en las regiones asiáticas. Estas fueron objeto de ocupación territorial y de la expulsión de ${ }^{20}$ La disolución de la colaboración entre antropólogos y medios de comunicación comenzó a cambiar alrededor de 1963, principalmente debido a tres condiciones: la regularización de la transmisión de la televisión (1963), la formalización del apoyo institucional para la investigación en el extranjero, a cargo de la Secretaría de Educación, Ciencia y Cultura (1963), y la liberación de los viajes al extranjero (1964) (Iida, 2007: 263-269).

${ }^{21} \mathrm{La}$ mitad del volumen de esta serie fue acerca de las civilizaciones antiguas de América. Los demás trataron de las civilizaciones alrededor de Angkor, localizado actualmente en Camboya, de Egipto y de África (Koizumi, 1976: 296). 
las tropas europeas (bajo el impulso imperial japonés), y a la vez, objeto de investigación para los etnólogos. Lo obvio es que, en un cierto tiempo inmediato después de la derrota en la Guerra, por lo menos hasta mediados de los años cincuenta, la otredad Asia ya no podía ser el objeto único de la mirada directa de los políticos ni de los académicos japoneses. En este contexto social tanto la antropología como los medios de comunicación se enfrentaban a la necesidad de buscar nuevos objetos, con una visión más amplia dirigida a otras regiones del mundo. Supongo que fue durante el proceso de búsqueda de nuevos objetos que surgió la mirada hacia el sujeto maya. Sin embargo, dicha mirada ya no fue igual a la que se dirigía de manera directa a la otredad Asia, sino una mirada indirecta o, mejor dicho, una visión que refleja parcialmente la figura de la otredad maya que se había construido en Occidente.

Con ese cambio de interés político ha surgido una mirada japonesa distinta hacia los espacios desconocidos. Eso implica la expectativa de encontrar en el Otro una semejanza con Nosotros. Un ejemplo significativo de ello serían las palabras de escritores del tiempo de la posguerra, como el ensayista Yoshino y el antropólogo Ishida, citadas al principio del texto. En ellas Yoshino expresaba la nostalgia que sentía frente a la ciudad Tokio, destruida por los bombarderos durante la Guerra (Yoshino, 1963: 4). El autor asoció la destrucción que ocurrió en Tokio, con la ciudad antigua de México que igualmente fue destruida por la violencia.

De la misma forma, el antropólogo Ishida hace un comentario sobre un sentimiento nostálgico que le provocó su viaje por México (1971: 49-50). Al subir al autobús en el campo, veía que la mayoría de los pasajeros "tienen los mismos rasgos Mongoloides, el origen de nuestra población asiática”. Ellos son "los descendientes de la gente que construyó estas ruinas", y en el tiempo presente "siguen viviendo con sus culturas y lenguas originales" (ibídem: 49). Al final de su texto, Ishida cierra con estas palabras: "México fue la tierra más nostálgica para mí entre los países que he visitado” (ibídem: 50).

Agrego un comentario pequeño del artista Taro Okamoto, quien señala la emoción que le genera, en el fondo de su propio cuerpo, el percibir la cultura maya (Namikawa, 1972: 199): "los dioses mayas se consideran muy extraordinarios debido a su intimidad, a la vez, a su grandeza. Pienso en la conexión consanguínea de los antepasados lejanos". 
Una figura alternativa de la otredad maya que estoy tratando de señalar con estas voces, quizá en una parte coincide con el Otro que se sitúa dentro de "lo mismo" en Occidente, que también Castañeda discutía en su texto. Según su argumento (Castañeda, 1996), la otredad maya para Occidente se ha figurado en la ambigüedad de presentarse dentro y, a la vez, fuera de Occidente. El discurso construido en Occidente sobre "el misterio de la civilización maya desaparecida" se entiende como algo entrelazado y fundido, imbuido de una ambigua otredad. Por otra parte, el discurso sobre la otredad maya que figura en las palabras citadas de los intelectuales japoneses no implica la expectativa de la asimilación de la otredad en Nosotros, sino la de la expulsión de Nosotros en el Otro para encontrar la semejanza con ellos. En otras palabras, considero esto como una práctica de buscar un Nosotros en el Otro situándonos en el espacio histórico de ellos. El sentimiento de nostalgia expresado por los intelectuales japoneses sería una metáfora significativa de esta figura de la otredad maya: su voz nostálgica suele transmitirse de Nosotros al Otro produciendo vibración de lo pasado común, por la cual el Nosotros puede sentirse comunicado con Ellos.

No obstante, el mecanismo sigue el mismo destino discursivo: lo pasado dibujado por los autores ha sido asociado con la imagen de la desaparición. Tanto la nostalgia que los intelectuales sentían por un pasado común, como la percepción del misterio estructurada en las series de Hikyo, han provocado la idea de "la desaparición", que situa fijamente a los mayas en un espacio dramatizado e inventado, con un discurso sobre el origen y el fin de su historia. Como el historiador británico Eric Hobsbawm ha señalado en su discusión sobre la invención de la tradición, "Las tradiciones que parecen o reclaman ser antiguas son a menudo bastante recientes en su origen, y a veces inventadas" (Hobsbawm, 2002: 7). Lo pasado no es sino algo que se ha seleccionado, escrito, popularizado e institucionalizado durante el proceso de la formación de la nación moderna y del conocimiento histórico (ibídem: 20). Hobsbawm ubica su discusión principalmente dentro del contexto de la formación de la nación británica; sin embargo, considero que su reflexión podría aplicarse a la invención de lo pasado en la otredad maya en el discurso construido en Japón. Hay una discontinuidad histórica entre pasado y nuestro presente. En este intervalo se presenta una proyección de la otredad maya imaginada mediante la asociación con "nuestro" propio pasado nostálgico. Así fue construido 
el entramado de narrativas (re)producidas sobre los mayas: las palabras e imágenes artísticas, literarias, ocultistas y antropológicas se relacionaron entre ellas y participaron recíprocamente en el proceso de construir, mediante sus específicos ojos históricos, un modo de ver a los mayas en la primera época de la posguerra en Japón.

\section{Bibliografía citada}

Benjamin, Walter, (2003) La obra de arte en la época de su reproductibilidad técnica. México: Editorial Itaca.

Bizyutsu Syuppan (editor), (1955) Bizyutsu Hihyo (Crítica de arte). Núm. 46, Japón.

Castañeda, Quetzil E., (1996) In the museum of Maya culture, Touring Chichén Itzá. Inglaterra: University of Minnesota press.

Clifford, James, (1995) Dilemas de la cultura. Antropología, literatura y arte en la perspectiva posmoderna. Espańa: Editorial Gedisa, S.A.

Escalona Victoria, José Luis, (2017) "La manufactura de los mayas. Los orígenes de una epistemología política del presente” en Alejandro Agudo Sanchíz, Marco Estrada Saavedra y Marianne Braig edi. Estatalidades y sobreranías disputadas: la reorganización contemporánea de lo político en América Latina. México: El Colegio de México, Centro de Estudios Sociológicos. Pp.117-143.

Evans, R. Tripp, (2004) Romancing the Maya. Mexican antiquity in the American imagination 1820-1915. Estados Unidos: University of Texas Press.

Foucault, Michel, (1995) Las palabras y las cosas. México: Siglo Veintiuno Editores.

Fujii, Eriko, (2010) Hibigakuteki haikyo ron (No-esteticismo de las ruinas). Tesis de licenciatura. Japón, Universidad de Kobe.

Hijikata, Teiichi, (1955), “Osorubeki zoukeiryoku” (El arte plástico poderoso), en Matutino del Yomiuri Shibun. Pp. 7.

Hobsbawm, Eric, (2002) [1983] La invención de la tradición. España: Editorial Critíca. 
Hooper-Greenhill, Eileen, (1992) "What is a museum" en Museum and the shaping of knowledge. Inglaterra: Routledge, pp. 12-33.

Hozaki, Hironori, (2018) "Mekishiko bizyutsu no syogeki. 1955 nen no 'mekishiko bizyutsu-ten' to Akutagawa Saori” (Impacto de las artes mexicanas. Las artes mexicanas de 1955 y Saori Akutagawa), en Art Paper, vol. primavera, pp.1-2.

Iida, Taku, (2007) "Syouwa sanzyunendai no kaigai gakuzyutsu expedition -'nihon no zinruigaku' no sengo to mass media-" (Expediciones académicas en extranjero en 1955-1965 -'antropología japonesa' en el tiempo de la posguerra y los medios de comunicación) en Kokuritsu minzokugaku hakubutsukan kenkyu houkoku. Vol.31, tomo 2, pp.227285.

Iikura, Yoshiyuki, (2009) “Utuskushii chikyu no 'Hikyou' -'ocult' no Youran toshiteno 1960 nendai 'hikyou' boom" (Hikyo en la tierra maravillosa -la popularización de Hikyo en la década de 1960 como la cuna del ocultismo-), en Morio Yohida ed. Ocult no wakusei 1980 nendai, mouhitotsu no sekai chizu. Japón: Seikyu sha. pp.19-40.

Instituto Nacional de Bellas Artes, et al. (1955) Mexico bizyutsu ten zuroku (Catálogo de Las artes mexicana). Japón: Yomiuri Shinbunsya.

Ishida, Eiichirou, (1971) [1967] Maya bunmei. Sekaishi ni nokoru nazo (Civilización Maya. Un misterio en la historia universal). Reimprimido en Ihida Eiichirou Zensyu dai 7 kan, Japón: Chikuma Syobou, pp.237-403.

Iwanami Shoten editores, (2013) [2008] Koujien [Versión digital]. Tokio, Japón: Iwanami Shoten.

Kaneko, Takechi, (2009) "Okaruto japan no bunsuirei -zyunsui bungaku toshiteno zinruigaku kara no ketsubetsu” (Cuenta del ocultismo japonés), en Morio Yohida (editor). Ocult no wakusei 1980 nendai, mouhitotsu no sekai chizu. Tokio, Japón: Seikyu sha, pp.41-62.

Kato, Kaoru, (2008) "Nihon gendai bizyutsu ni okeru mexico hekiga undou no eikyou ni tsuite" (Un estudio sobre la influencia del movimiento muralista de México en Artes contemporáneos japoneses) en Kirin. Vol.17, pp. 58-41.

Koizumi, Gentaro (traductor), (1976) [1968] Carnegie Institution for Science, en Ushinawareta Maya oukoku-yukatan hantou ni kieta maboroshi no 
minzoku (Reino desaparecido maya-la misteriosa etnia desaparecida en la península Yucatán). Japón: Tairiku Syobou.

Lara, Luis Fernando (dir.), (2011) [2010] Diccionario del español de México, Centro de Estudios Lingüisticos y Literarios. México: Colegio de México. Miyamoto, Saburo, (1955) "Kyoretsu na hakuryoku, minzoku-syu” (Impacto inmerso, aroma de las etnias), en Matutino del Yomiuri Shibun. p. 3.

Nakano, Yasuo, (2004) "Okamoto Taro Mekishiko heno manazashi" (Taro Okamoto. Su mirada a México), en Catálogo de la exposición Atsui manazashi Okamoto Taro to Mekishiko.

Namikawa, Banri, (1972) Maboroshi no maya-bunmei: Mekishiko no iseki to bunka-isan (Civilización imaginaria maya: ruinas arqueológicas y patrimonio cultural de México). Tokio, Japón: Keisyosya.

Ochiai, Kazuyasu, (2006) "Introducción" en El mundo maya: miradas japonesas. Ciudad de México: UNAM, pp.7-14.

Okamoto, Taro, (1975) "Shi to sei to souzou to" (Muerto, vida y creación), en Tomohiro Takayama edi, Grand sekai bizyutsu, 25 kan Maya to Inca no bizyutu. Tokio, Japón: Kodansya, pp. 98-104.

Said, Edward W., (2002) [1997] Orientalismo. Barcelona: Randam House Mondadori, S.A..

Sakurai, Mieko, (2004) "Maya kenkyu shi wo tadoru” (Reflexión de la historia de estudios mayas) en Osaka keidai ronsyu. vol. 54, núm. 5, pp. 239254.

Sukikara, Fumiko, (2019) Formación y transformación en la narrativa del Popol Vuh: las publicaciones y las prácticas de traducción al japonés, 19281971. Tesis para obtener el grado de maestría. México, Instituto de Estudios Indígenas, Universidad Autónoma de Chiapas.

Tezuka, Osamu, (1999) [1955] "Tetsuwan Atom Reito-ningen no maki" (Hombre congelado en Tetsuwan Atom) en Brutas tosyokan tezuka osamu. Magazine House, junio, pp. 45-75.

Yoshino, Saburo, (1963) Maya to Azteca (Maya y Azteca). Tokio, Japón: Syakai Shisou Sya.

\section{Bases de datos en línea}

Asahi Shinbun, (2018) Kikuzo II visual. Disponible en: http://database.asahi. com/index.shtml (Consultado: 22 de mayo de 2018). 
Fumiko Sukikara

Biblioteca de la Dieta Nacional, (2018) Collections [online]. Disponible en: http://iss.ndl.go.jp/ (Consultado: 31 de agosto, 2018).

Housou library (Biblioteca de emisión), (2018). Disponible en: http://www. bpcj.or.jp/ (Consultado: 29 de septiembre, 2018).

Mainichi Shinbun Miasaku, (2018) Disponible en: https://dbs.g-search.or.jp/ WMAI/WMAI_ipcu_login.html (Consultado: 22 de mayo de 2018). Yomiuri Shinbun Yomidasu, (2018) Disponible en: https://database.yomiuri. co.jp/rekishikan/ (Consultado: 22 de mayo de 2018). 